\title{
Hans Max Hirschfeld. De juiste man op de juiste plaats...?
}

\section{Madelon de KeIZer}

Nog geen drie jaar na de publicatie van de 'halve' biografie van H.M. Hirschfeld door Arie van der Zwan ${ }^{1}$, verscheen onlangs Hirschfelds levensbeschrijving van de hand van de Amsterdamse politicoloog Meindert Fenne$\mathrm{ma.}^{2}$ Daarin gaat het niet meer alleen om de carrière van de Haagse topambtenaar Hirschfeld voor de oorlog en diens positie als secretaris-generaal van Handel, Nijverheid en Scheepvaart, en daarbij ook nog eens Landbouw en Visserij in bezettingstijd, maar is ook zijn rol in de Nederlandse politiek na de oorlog onder de loep genomen. $\mathrm{Na}$ de voor hem gunstig uitgevallen zuivering in 1946 werd Hirschfeld opnieuw de Haagse toponderhandelaar in de Nederlandse economische belangenbehartiging in het internationale veld. Fennema's geschiedschrijving van deze episode in het leven van Hirschfeld vormt een welkome aanvulling op onze kennis over de man die door de columnist J.L. Heldring Nederlands machtigste ambtenaar ooit is genoemd. Dat hield in ieder geval veel meer in dan de subtitel van Fennema's biografie suggereert: 'Man van het grote geld'.

Sua fata habent libelli: deze Hirschfeld-studie van de hand van twee auteurs kent inderdaad een hele geschiedenis. Fennema deed er uitvoerig en hier en daar, naar mijn smaak althans, ongeremd verslag van in een artikel in het Biografie Bulletin. ${ }^{3}$ Midden jaren tachtig had zijn promovendus John Rhijnsburger zich op het onderwerp gestort. Zijn onderzoek richtte zich op de vraag wat het Nederlands belang was en hoe dit belang veranderde tussen 1931 en 1952, tussen het aantreden van Hirschfeld als directeur-generaal van Handel en Nijverheid en zijn aftreden als regeringscommissaris voor de Marshallhulp. Rhijnsburger bleek een ondernemend en gewaardeerd onderzoeker, maar in zijn persoonlijk leven reeg de ene ramp zich aan de andere. In 1999 overleed hij, na Fennema te hebben verzocht zijn boek af te maken. Fennema besloot evenwel een biografie van Hirschfeld te schrijven. Zo kon hij ook de resultaten van Rhijnsburgers onderzoek benutten dat strikt genomen buiten de door hem onderzochte periode viel.

$\mathrm{Nu}$ liggen er dus twee biografieën over dezelfde persoon, kort na elkaar verschenen: dat is ongekend in een land waarvan de uitgevers doorgaans beweren dat het lezerspubliek daarvoor veel te klein is. Betrekt men daarbij ook nog het niet geringe aantal recente publicaties van betekenis waarin

1 Arie van der Zwan, H.M. Hirschfeld. In de ban van de macht (Amsterdam 2004).

2 Meindert Fennema en John Rhijnsburger, Dr. Hans Max Hirschfeld. Man van het grote geld (Amsterdam 2007).

3 Meindert Fennema, 'Monument voor een gestorven jongen. De sociogenese van een Hirschfeldbiografie', Biografie Bulletin (2007) 82-86. 
Hirschfeld een niet onbelangrijke rol speelt, dan lijkt het niet overdreven om te spreken van het bestaan van een zekere fascinatie, van een obsessie misschien wel met Hirschfeld, vooral in het afgelopen decennium. Zo verscheen in 2002 het standaardwerk van Hein Klemann over de economie en de samenleving van Nederland in de periode 1938-1948 (waarin een heel hoofdstuk wordt gewijd aan de man) en een jaar later het chef d'oeuvre van Joggli Meihuizen over de bestraffing van economische collaboratie in Nederland na de Tweede Wereldoorlog (waarin met name het eerste hoofdstuk essentiële kost is voor de in Hirschfeld geïnteresseerde). ${ }^{4}$

We zouden nu dus deskundig en optimaal geïnformeerd moeten zijn over het leven van Hirschfeld, over de economische context waarin hij opereerde, over de manier waarop hij be- en veroordeeld werd in de naoorlogse bijzondere rechtspraak en (bedrijfs-)zuivering en - speciaal met Fennema's studie nu - over zijn naoorlogse periode, als de man die grote economische klussen klaarde als de Marshallhulp en de afwikkeling van de dekolonisatie van Indonesië. En dat is ook zo. Toch durf ik zonder meer de weddenschap aan dat ook met Fennema's biografie, hoe uitvoerig en diepgaand ook de schrijver op zijn onderwerp ingaat, niet het laatste woord gezegd zal zijn over deze op zich weinig tot de verbeelding sprekende secretaris-generaal, die niettemin in Nederland hetzij met grote bewondering hetzij met diep afgrijzen werd en wordt genoemd. Ik wil mij in deze bijdrage bepalen tot het debat over Hirschfelds beleid in de jaren 1940-1945 en daarmee, zoals het een onderzoeker van het NIOD tenslotte betaamt, opnieuw de open zenuw blootleggen in de geschiedschrijving over Nederland in bezettingstijd. ${ }^{5}$

Scherp herinner ik mij hoe de illegale redacteur van Het Parool Jan Meijer, toen ik hem begin jaren negentig voor mijn boek over het illegale Parool interviewde, niet anders dan met diepe minachting en grote woede over Hirschfeld kon spreken. De jonge Haagse econoom Meijer, die over betrouwbare inside information beschikte over wat er op Hirschfelds departementen zoal omging, had zich als de principiële tegenstander van de secretarisgeneraal opgeworpen. In januari 1944 schreef hij in het illegale Parool het befaamde artikel met de titel 'Hirschfeld's immoreel beleid'. Hij reageerde daarin op ambtelijke instructies van Hirschfeld aan zijn ambtenaren:

Wij hebben zijn woorden driemaal herlezen voor wij het waagden te gelooven, dat de instructies die Hirschfeld zijn naaste medewerkers geeft, werkelijke zoo immoreel zijn. Op het oogenblik dat het Nederlandsche volk lijdt onder een gruwelijke Duitsche terreur, dat

4 Hein A.M. Klemann, Nederland 1938-1948. Economie en samenleving in jaren van oorlog en bezetting (Amsterdam 2002) hoofdstuk 14, 'Hirschfeld: "eine angemessene Versorgung der Bevölkerung als Rechtfertigung"', 491-533; Joggli Meihuizen, Noodzakelijk kwaad. De bestraffing van economische collaboratie in Nederland na de Tweede Wereldoorlog (Amsterdam 2003).

5 Hoezeer Hirschfeld nog steeds aanleiding tot fel debat aanleiding kan geven bleek bij de presentatie van Fennema's biografie, toen de derde spreker Frits Bolkestein, voor zijn doen nogal emotioneel, ter plekke de aanval opende op mijn betoog, dat in deze bijdrage verder is uitgewerkt. 
elk gevoel van eerlijkheid en recht wordt verkracht, dat honderdduizenden gezinnen door slavendrijvers uiteen zijn gescheurd, dat ontelbaar velen het zware bestaan leiden van ondergedokenen, dat in gevangenissen en concentratiekampen de besten uit ons volk worden gemarteld en gedood omdat zij karakter toonden, op dat zelfde oogenblik gelast Hirschfeld van achter de groene tafel in zijn Departement, dat de politiek zooveel mogelijk buiten onze werkzaamheden gehouden moet worden.

Daarmee was de toon gezet. Hirschfelds centrale positie in het economisch leven in bezettingstijd roept inderdaad een fundamenteel ethische vraag op: zijn het de economische, materiële waarden die ten allen tijde moeten prevaleren of zijn er daarnaast nog andere waarden, geestelijke, humanistische of christelijke, die eveneens in aanmerking moeten worden genomen of wellicht zelfs zwaarder moeten wegen?

Inmiddels kan het geen punt van discussie meer zijn dat Hirschfelds aanblijven en optreden in bezettingstijd een kwestie was van economische collaboratie, al dan niet strafbaar. De rechtshistoricus Meihuizen heeft dat overtuigend aangetoond. Met Hirschfeld waren de Rotterdamse havenbaronnen zich daarvan trouwens heel goed bewust. ${ }^{6}$

Het is echter interessant te zien dat historici grote moeite hadden en hebben met deze visie op Hirschfeld. Dat was overigens niet het geval met Loe de Jong, die in Het Koninkrijk der Nederlanden in de Tweede Wereldoorlog uitvoerig op Hirschfelds doen en laten in oorlogstijd is ingegaan. Hij had over Hirschfelds optreden in bezet Nederland een heel duidelijk opvatting. Het ging hier inderdaad om een geval van economische collaboratie, hulp aan de vijand dus - met alle begrip overigens voor de economische context waarin Hirschfeld had te opereren en de keuzen waarvoor Hirschfeld zich gesteld zag.

Maar De Jongs geschiedschrijving is vanaf het begin van de jaren tachtig onder vuur komen liggen. Zijn beoordeling in termen van hulp aan de vijand of steun aan het verzet, van goed of fout, zou een te zwart-wit beeld hebben gegeven van de bezettingstijd. Er speelden destijds immers ook nog zo veel andere vraagstukken dan collaboratie en verzet. Velen zagen zich bijvoorbeeld nimmer voor een dergelijke keuze gesteld. En wie wel voor de keuze stond moest kiezen welke overwegingen van welke aard bij het bepalen van zijn of haar houding zouden prevaleren. Wie bovendien de oorlog in andere termen wilde zien en als een totale oorlog, als een centraal conflict in de wereld van de twintigste eeuw wilde begrijpen, diende helemaal andere vragen te stellen dan die naar goed of fout, naar collaboratie of verzet. Dat was een belangrijke gedachte die destijds in de Europese historiografie over de Tweede Wereldoorlog algemeen postvatte en die in 1983 door Hans Blom in zijn bekende inaugurele rede werd verdedigd. ${ }^{7}$

Blom meende echter de interpretatie te dienen door de ethiek uit te schakelen. ${ }^{8}$ Dat is niet alleen onmogelijk, maar ook onwenselijk. Als een

6 Meihuizen, Noodzakelijk kwaad, 147.

7 J.C.H. Blom, 'In de ban van goed en fout? Wetenschappelijke geschiedschrijving over de bezettingstijd in Nederland' (oratie 1983), onlangs herdrukt in J.C.H. Blom, Noodzakelijk kwaad. Geschiedschrijving over de bezettingstijd in Nederland (Amsterdam 2007) 9-29. 
historicus immers al één ding weet dan is het wel dat zoiets per definitie een onmogelijke eis is. Ethiek is nu eenmaal inherent aan de geschiedschrijving en maakt er dus een integraal onderdeel van uit. Iedere geschiedschrijving, zelfs die van de vermaledijde Sonttabellen, die in dit soort discussies altijd als voorbeeld worden genoemd, is zingeving. Het is naar de smaak van de historicus om die zingeving impliciet te laten of expliciet te maken.

Elke historicus kent daarom dan ook nog de historicus Pieter Geyl, generatiegenoot van Loe de Jong, die concludeerde dat geschiedschrijving 'een discussie zonder eind' was. Immers, schreef hij: 'Iedere historische voorstelling is van verklaring, interpretatie, waardering afhankelijk'. Dat liet hij zien aan de hand van de manier waarop Napoleon, een minstens zo'n intrigerende figuur als Hirschfeld, in de Franse geschiedschrijving was beschreven. Dat was in het voorjaar van 1940, anders dan men misschien zou denken, een hoogst actueel onderwerp. Hoe actueel blijkt wel uit de slotbeschouwing, waarin Geyl schreef dat het die Franse geschiedschrijving ontbrak aan 'de eeuwige postulaten van eerbied voor de menselijke persoonlijkheid, van zin voor geestelijke vrijheid, van hoog idealisme, van waarachtigheid ${ }^{10}$ - waarden die in juni 1940, toen het artikel werd gepubliceerd, al plaats hadden moeten maken voor de pseudo-moraal van het Derde Rijk, en precies die waarden die Jan Meijer vier jaar later in zijn tirade tegen Hirschfeld in het illegale Parool fel verdedigde.

Welke context men ook kiest, hoe diep en wijd men het net van zijn onderzoekingen ook werpt, uiteindelijk komt de historicus zichzelf tegen. En uiteindelijk zal de lezer of zullen de media juist in dat oordeel van de historicus geïnteresseerd zijn, in de visie die uit zijn of haar geschiedverhaal spreekt. Zo bezien vormt Fennema's biografie van Hirschfeld een interessante bijdrage aan het debat over ethiek en geschiedschrijving.

Ook hij werpt, zoals het een goed historicus en politicoloog betaamt, het net diep en wijd. Waardevol is de aandacht die hij vraagt voor Hirschfelds Saint-Simonisme. Volgens die maatschappijvisie, die Hirschfeld zijn hele leven lang zou hebben gehad en die de drijfveer van zijn handelen zou zijn geweest, dienden bankiers, wetenschappelijk geschoolde ingenieurs en economen een leidende rol in de samenleving te vervullen. Daarbij moet worden aangetekend dat Hirschfeld in die maatschappijvisie zeker niet alleen stond. Zijn ideeën werden in de brede laag van de economisch actieve grootburgerij sedert 1890 gedragen. Van dergelijk gedachtegoed was zelfs een hele nieuwe klasse doortrokken, bestaande uit technocraten, vooral ingenieurs en economen; uit mensen die Nederland (en de wereld) eindelijk eens op orde wilden brengen, zoals de waterbouwkundig ingenieur Cornelis Lely (de man van de Afsluitdijk), maar ook iemand als NSB-leider ingenieur Anton Mussert. Niet alleen in Nederland maar in heel Europa makte die zakelijke klasse met zijn zakelijke waarden furore tijdens de Eerste Wereldoorlog en het interbellum. De

8 Zie hiervoor ook Chris Lorenz, De constructie van het verleden. Een inleiding in de theorie van de geschiedenis (Meppel en Amsterdam 1987) 261-264.

9 Pieter Geyl, Napoleon voor en tegen in de Franse geschiedschrijving (Utrecht 1965) 4-5.

10 Ibidem, 504. 
vermoorde Duitse politicus en econoom Walther Rathenau was bijvoorbeeld ook zo iemand. Het is een gemiste kans dat de econoom Van der Zwan, die wel goed oog heeft voor Hirschfeld als lid van die opkomende maatschappelijke klasse van leiders van het toekomstige economische leven, van die managersklasse, niet dat facet tot leidraad van zijn biografie heeft genomen. Het sociale modernisme van deze technocratische cultuurdragers richtte zich namelijk tegen het verleden en beoogde een herboren cultuur. Dit streven naar een volkomen vernieuwing makkte ook de kern uit van het fascisme. ${ }^{11}$ In een poging Hirschfelds deutschfreundlichkeit te peilen raakt Van der Zwan echter helaas de weg kwijt in de weliswaar sensationele maar door de lezer oncontroleerbare en, voor zover na te gaan door de auteur vrijwel ongecontroleerde documenten van de Binnenlandse Veiligheidsdienst.

Opgemerkt moet worden dat die technocratische klasse de politiek - dat strijdtoneel per definitie van waarden en belangen - als een verderfelijke bezigheid beschouwde. De democratie zag men als gekeuvel van tandeloze en hersenloze politici, die geen idee hadden van wat werkelijk in de samenleving speelde, geen benul hadden van het enorme potentieel en de ijzeren wetten van de economie. En daarbij geen inzicht hadden in wat werkelijk telde: een samenleving waarin zo weinig mogelijk materiële ellende geleden werd. Alleen zo was een revolutie binnen het georganiseerde kapitalisme te bezweren, aldus de maatschappijvisie van deze pragmatische realisten.

Voor de oorlog leidde die kijk op de samenleving tot een door Hirschfeld gesteunde bilaterale handelspolitiek met het Derde Rijk waarin inderdaad geen andere dan economische waarden telden. Er werd een op aanpassing aan de belangrijkste handelspartner van Nederland gericht beleid gevoerd, dat in feite een beleid van appeasement was, omdat men geloofde op die manier de vrede in Europa te bewaren. Beide partners waren immers weinig gebaat bij een verdere ontwrichting van de economische toestand en beide hadden belang bij wederzijdse toenadering. Hirschfeld was de voornaamste onderhandelaar met Duitsland en trachtte daarbij zoveel mogelijk politieke interventies in zijn beleid te weren. Nederland was toen echter een democratie waarin verantwoording voor dit beleid diende te worden afgelegd. ${ }^{12}$

Belangrijk van Fennema's studie is dat hij laat zien hoe dit technocratisch beleid ook na 1945 werd gecontinueerd. Ook nu weer trachtte Hirschfeld zich welbewust en zoveel hij kon aan democratische controle te onttrekken. Bij elke klus waarvoor hij werd gevraagd - nee: waarvoor men hem smeekte die op zich te nemen - bedong en kreeg hij wat dat betreft een uitzonderingspositie. Maar toen was Nederland opnieuw een democratie en in die democratie konden in beginsel de homo politicus en de homo economicus in alle openbaarheid de strijd met elkaar aangaan.

Maar in bezettingstijd ging dat zo niet. $\mathrm{Na}$ de Duitse inval had de homo economicus Hirschfeld het vooroorlogs beleid zonder meer voortgezet - vrij

11 Zie hiervoor Roger Griffin, Modernism and Fascism. The Sense of a Beginning under Mussolini and Hitler (Houndmills en New York 2007).

12 Madelon de Keizer, Appeasement en aanpassing. Het Nederlandse bedrijfsleven en de DeutschNiederländische Gesellschaft 1936-1942 ('s-Gravenhage 1984). 
('verlost' zei hij zelf) van democratische controle door politici. Maar nu was het niet langer meer aanpassing en appeasement, maar ging het om hulp aan de vijand. De waarden van waaruit men toen vocht tegen de bezetter, vooral die van vrijheid en onafhankelijkheid, kwamen scherp in botsing met die van de technocraat Hirschfeld, die zich bewust onttrok aan elke vorm van overleg. En juist dat vormde de reden van Jan Meijers rabiate woede. Want hoewel zich in bezet Nederland vrijwel vanaf het moment van de capitulatie een illegaal politiek bestel ontwikkelde waarin mensen van grote faam en deskundigheid een rol speelden, en hoewel op zeker ogenblik ook de betrekkingen met Londen regelmatig overleg met de regering mogelijk maakte, weerde Hirschfeld iedere vorm van beraadslaging dan ook af - ja achtte hij verzet tegen de Duitsers ondermijning van zijn beleid.

Over Hirschfelds beleid in oorlogstijd zal dan ook altijd worden gestreden. Want wie oog heeft voor de overlegmogelijkheden in oorlogstijd, voor het illegaal politiek bestel met zijn omvangrijke, welingelichte en zeer kritische illegale pers, ziet Hirschfeld als een onvergeeflijke eigengereide economisch collaborateur. Zo ziet L. de Jong hem, en zo zie ik hem ook. De twee pagina's die de behoedzame politicoloog Hans Daalder in zijn Drees-biografie heeft gewijd aan Hirschfeld en zijn zuivering zeggen genoeg: juist Drees, die een uiterst complexe positie innam in het illegaal politiek bestel, bleef altijd ambivalent tegenover Hirschfeld. Hij was 'een man ... die zeer opportunistisch handelde', zei Drees in de ministerraad in april $1946 .{ }^{13}$

Had Hirschfeld gelijk met zijn politiek van economische collaboratie ten bate van de Nederlandse bevolking? Of bracht hij door op zo'n eigengereide manier op zijn post te blijven Nederland ethisch beschouwd grote schade toe, zoals Meijer poneerde? In de recent verschenen studie Burgemeesters in oorlogstijd van Peter Romijn draait het om eenzelfde vraag: deden de burgemeesters er goed aan zo lang mogelijk aan te blijven, of was het beter geweest - gezien de aanzwellende stroom van onverkwikkelijke zaken waarin zij werden meegesleurd - om direct ontslag in te dienen en de vijand zoveel mogelijk te boycotten? De onderzoeksstrategie van Romijn is in concrete gevallen te analyseren wat de bedoelingen van de betrokken burgemeester zijn geweest en hoe hij zijn optreden wist te legitimeren tegenover zijn gemeente. Een categorisch antwoord op de vraag 'opstappen of aanblijven?' valt zijn inziens niet te formuleren. ${ }^{14}$ Ook de man die destijds de belangrijkste arresten van de Bijzondere Raad van Cassatie had geconcipieerd, mr. D.J. Veegens, was al van mening geweest dat de grens tussen geoorloofde en ongeoorloofde hulpverlening aan de vijand heel moeilijk te bepalen was. 'Het probleem is uiteindelijk onoplosbaar', zei hij tegen Meihuizen. ${ }^{15}$ Doeko Bosscher stelt dan ook terecht vast in een bespreking van Romijns studie dat de principiële vraag 'aanblijven of niet' in wezen niet kan worden beantwoord, maar wel altijd een

13 Hans Daalder, Gedreven en behoedzaam (1886-1988). De jaren 1940-1948 (Amsterdam 2003) 340-341.

14 Peter Romijn, Burgemeesters in oorlogstijd. Besturen onder Duitse bezetting (Amsterdam 2006).

15 Meihuizen, Noodzakelijk kwaad, 745. 
onderzoeksvraag moet zijn. ${ }^{16}$

Wat is nu Fennemas antwoord op die vraag? Had Hirschfeld moeten opstappen? Een economisch collaborateur vindt Fennema Hirschfeld niet; hij schrijft: 'Zijn vijanden beschouwden hem als economisch collaborateur' (319). Hirschfelds aanblijven ziet hij als een logisch gevolg van de Aanwijzingen van 1937. Dat argument hoort men wel vaker. Maar Meihuizen heeft overtuigend laten zien dat het hier om een informeel besluit gaat dat was vervaardigd door ambtenaren van Defensie en Binnen- en Buitenlandse Zaken. Daarbij waren wel humanitaire hulp en welomschreven diensten aan de vijand geoorloofd, maar betekenden alle overige vormen van samenwerking 'hulpverlening aan de vijand', zoals strafbaar gesteld in art. 102 van het Wetboek van Strafrecht. ${ }^{17}$ De kern van de richtlijnen die in de Aanwijzingen zijn vervat is dat de ambtenaar gehouden is zelf een bestuurlijke afweging te maken wat men wel en niet kan accepteren, schrijft Romijn. In 1943 kreeg dit stuk nadere uitleg in het Commentaar, waaruit blijkt dat de Aanwijzingen niet op zichzelf stonden, maar moesten dienen 'als het ambtelijk vertrekpunt in een besluitvormingsproces, waarin ook andere dan ambtelijke overwegingen een rol speelden: politieke opvattingen, wereldbeschouwingen, plichtsbesef en gewoon fatsoen' ${ }^{18}$ De bestuurder die op een bepaald moment een juist bestuurlijk oordeel wilde vellen, was, zo benadrukt Romijn, dus genoopt tot een bredere politieke consultatie. Voor dat laatste was Hirschfeld echter beslist niet te vinden - en dat was nu net ook de reden waarom hij voor de bezetter zo bruikbaar was. Fennema heeft voor het illegaal politiek bestel als speler in bezet Nederland geen enkel oog. Hirschfeld, schrijft hij, moest 'bijna geheel op eigen kompas varen en kon alleen zijn naaste collega's die hij geheel meende te kunnen vertrouwen om advies vragen' (319). Aan dergelijke kwaliteitseisen voldeden een Drees of een Meijer in Hirschfelds (en Fennema's) ogen kennelijk niet.

Een groot manco van de Aanwijzingen was, schrijft Romijn, het ontbreken van een verbod om mee te werken aan racistische politiek. Zoiets had men in 1937 vanwege de vooroorlogse neutraliteitspolitiek maar liever buiten beschouwing gelaten. ${ }^{19}$ In een in 2001 gepubliceerd artikel schreef Fennema dat Hirschfeld, gelet op de deportaties van de Joden in 1942, had moeten opstappen, omdat daarmee de vijand de integriteit van de samenleving aantastte. Ook al had dat alleen nog maar meer economische ellende over Nederland gebracht, toch had Hirschfeld zijn post moeten verlaten, 'want in deze extreme situatie stond het belang van de niet-Joodse bevolking tegenover het meewerken aan een zo monsterlijk programma dat het afwegen van het één tegen het ander zelf een onmenselijke daad werd [...] hier stuitte het utilitaire perspectief op de morele grens van de menselijke waardigheid'. ${ }^{20}$ In deze nieuwe Hirschfeld-biografie daarentegen - waarvan het betoog immers wordt

16 Doeko Bosscher, 'Het noodlot van de burgemeester in oorlogstijd', BMGN 122:2 (2007) 240.

17 Meihuizen, Noodzakelijk kwaad, 25-30, ook 647-648.

18 Romijn, Burgemeesters in oorlogstijd, 658.

19 Ibidem, 658.

20 Meindert Fennema, 'Hans Max Hirschfeld. Secretaris-generaal van een onthoofd ministerie (1940-1945), in: M. Fennema en C. Maris (ed.), Onrecht. Oorlog en rechtvaardigheid in de 
gedicteerd door Hirschfelds saint-simonisme - vinden we van die destijds weloverwogen positiekeuze van Fennema echter in het geheel niets meer terug. ${ }^{21} \mathrm{Nu}$ overweegt het argument dat Hirschfeld zelf hanteerde: door aan te blijven en met de bezetter samen te werken kon hij de Nederlandse bevolking van de hongersnood redden: 'We hebben laten zien dat hij daarin tot op grote hoogte gelijk had', aldus Fennema (321).

Ook bij Fennema moeten de geestelijke waarden het dus afleggen tegen de economische, de materiële. Op dat punt deelt hij de opvattingen van de economisch historicus Klemann, die na een minutieuze analyse van het optreden van Hirschfeld en zijn rechterhand S.L. Louwes in bezettingstijd in behoedzame bewoordingen concludeerde dat deze terecht waren aangebleven: 'Toch moet worden vastgesteld dat in Nederland de voedselsituatie zo precair was, dat zij niet konden gaan'. ${ }^{22}$

Fennema en Klemann vertegenwoordigen een generatie historici die zich aan de wurgende greep van de vader van de geschiedschrijving over Het Koninkrijk der Nederlanden in de Tweede Wereldoorlog, Loe de Jong, hebben trachten te ontworstelen. Zij zijn de leerlingen van Hans Blom, die in de jaren tachtig, vanuit de veilige positie van het toen vanzelfsprekende, dominante en homogene westerse democratische waardensysteem, het startschot gaf voor een geschiedschrijving waarin dat systeem, hoewel nog steeds impliciet aanwezig, niet langer de toetssteen mocht vormen. Mede op gezag van Maarten Brands stelde men toen dat het waardensysteem van de historicus bij de beoefening van het vak zoveel mogelijk overboord moest worden gezet: wat zou dat immers aan extra kennis over het verleden opleveren $?^{23}$ De geschiedschrijving concentreerde zich sedertdien op deelwaarden, waarbij het moreel potentieel daarvan echter evenredig afkalfde. Het lege concept accommodatie (anders dan het 'volle', juridische, concept van collaboratie), dat als analysemodel voor de nieuwe geschiedschrijving over bezettingstijd ging fungeren, is daarvan het beste voorbeeld. Dit leidde in de jaren negentig tot een zogenaamde 'ontmythologiserende' geschiedschrijving, tot analyses van oorlog en bezettingstijd waarin daders, omstanders en slachtoffers zich oplosten in een 'grijs verleden'. ${ }^{24}$

twintigste eeuw. Twaalfde jaarboek van het NIOD (Zutphen 2001) 152-176, citaat op 173174.

21 Hoewel passages hiervan in de epiloog van de biografie staan, wordt het artikel zelfs niet meer in de bibliografie genoemd.

22 Klemann, Nederland 1938-1948, 533.

23 Maarten Brands, 'Over waarde van waarde-oordelen. Een reactie op Junker en Von der Dunk', in: Theo de Boer en André J.F. Köbben (eds.), Waarden en wetenschap. Polemische opstellen over de plaats van het waarde-oordeel in de sociale wetenschappen (Bilthoven 1974) 223-229, citaat 226. Brands refereerde uiteraard an het waardevrijheidsprincipe van Max Weber, dat echter alleen maar expliciete waardeoordelen veroordeelt. Waardevrijheid betekent uiteraard niet geen waarden te hebben.

24 Chris van der Heyden, Grijs verleden. Nederland en de Tweede Wereldoorlog (Amsterdam en Antwerpen 2001); zie bespreking van dit boek door Hans Blom in de BMGN 116:3 (2001) 483-489, herdrukt in Blom, Noodzakelijk kwaad, 57-67. 
Inmiddels, met het veranderen van de tijden na de eeuwwende, staan opnieuw de morele zorgen hoog genoteerd op de theoretische, culturele en politieke agenda. Wie Bloms afscheidsrede van dit voorjaar aandachtig leest, ziet hoezeer nu ook hij worstelt met vragen naar moraliteit en ethiek en dankbaar grijpt naar het door Bob de Graaff in zijn Utrechtse oratie voorgestelde concept van 'situationele ethiek'. ${ }^{25}$ Daarmee zijn we terug bij af. Vragen van morele aard behoren nu eenmaal tot de kern van de geschiedschrijving en kunnen ook wetenschappelijk besproken worden, bracht Maarten Brands, nog vers onder de indruk van 9/11, al in 2003 naar voren. ${ }^{26}$ Inderdaad. De waarde van een historische studie schuilt in de mate waarin het onderwerp begrijpelijker wordt en historisch meer verklaarbaar, zonder dat daarbij echter in morele zin alles wordt genormaliseerd, gerationaliseerd of in belang verkleind. Multiperspectiviteit - óók in een biografie - èn expliciete benoeming van wat er gebeurt of wat mensen doen - is dit een geval van collaboratie of niet? - zijn daartoe de geëigende instrumenten. ${ }^{27}$

Weliswaar weten we inmiddels dus veel meer over de persoon en het beleid van Hirschfeld en de economische context waarin hij opereerde, het ethische vraagstuk rond zijn positie in bezettingstijd is al met al niet van de baan. We zullen namelijk altijd gefascineerd blijven door de vraag of we het belang van de instandhouding van de maatschappelijke economische orde in oorlogstijd hoger moeten stellen dan het handhaven van zekere persoonlijke en collectieve fundamentele humanistische en christelijke waarden die door de vijand grondig werden vertrapt. Of het belang van het collectief boven dat van het individu ging (of, in dit geval, een groep van de Nederlandse samenleving: de Joden). Of het gaat om materiële of geestelijke waarden.

Dr. Madelon de Keizer is historicus en senior onderzoeker bij het NIOD. Recentelijk verscheen van haar hand De dochter van een gazan. Carry van Bruggen en de Nederlandse samenleving 1900-1930 (Amsterdam 2006). Op dit moment schrijft zij een biografie van Frans Goedhart (met Paul Arnoldussen) en een biografie van Albert Verwey.

25 Blom, Noodzakelijk kwaad, 155-179, 165.

26 M.C. Brands, 'Beslagen buitenspiegels. Over de grenzen van zelfreflectie in Nederland', in: Conny Kristel e.a. (ed.), Met alle geweld. Botsingen en tegenstellingen in burgerlijk Nederland 1930-1950 (Den Haag 2003) 45. Bij de presentatie van mijn studie Putten. De razzia en de herinnering in najaar 1998 had Brands overigens zoiets ook al geformuleerd: 'Natuurlijk is de historicus geen rechter, maar moreel afwegen blijft een essentieel onderdeel uitmaken van het werk van de historicus die zich bezighoudt, niet met de aanleg van de afsluitdijk of het sluiten van de mijnen, maar met de geschiedenis van onderdrukking en massale mensenvernietiging'. In bepaalde gevallen mag dat dus wel...

27 Christian Meier schreef dat een 'Verbrechen' alleen dan maar objectief wordt weergegeven als men het ook een 'Verbrechen' noemt. Christian Meier, Entstebung des Begriffs 'Demokratie: vier Prolegomena zu einer historischen Theorie' (Frankfurt 1970) 182-221; citaat op 214. Daarin hield hij eveneens een pleidooi voor een 'methodisch bewuszte(n) multiperspectivische(n) Geschichtsschreibung', Ibidem, 213. 
Summary

Madelon de keizer, Hans Max Hirschfeld. The Right Person in the Right Position...?

Fennema's biography of H.M. Hirschfeld represents an interesting contribution to the debate on ethics and historiography. After all, Hirschfeld's central position in the Dutch economy during the German occupation raises some fundamental ethical questions. Should economic and material values prevail at all times or should other values - moral, humanist or Christian - carry just as much weight, if not more? As opposed to the situation in the 1930s and the post-war years, during the German occupation the technocrat Hirschfeld was not democratically accountable for his policy. The author of this article explains that Hirschfeld's biographer mistakenly assumes that it is not necessary to include a discussion of the ethical aspects of Hirschfeld's continuation in public office during wartime. 


\section{Dr. Hans Max Hirschfeld, man zonder moreel kompas?}

Over de ontsporing van beeldvorming ${ }^{1}$

\section{ROBIN DE BRUIN}

In het liberale Haagse dagblad Het Vaderland van 9 oktober 1936 schreef de destijds befaamde columnist Eduard Elias onder het pseudoniem Bernard Buitenhof aan een imaginaire vriend over het veranderde uitgaansgedrag van de Haagse society. Veel Haagse mannen hadden volgens Buitenhof het goede gesprek in de Nieuwe of Littéraire Sociëteit (een herensociëteit, beter bekend als De Witte) ingeruild voor 'de sféér en de nootjes' in gelegenheden waar personen van beiderlei kunne werden toegelaten. Zelf zag Buitenhof ook liever Haagse jongedames dan de highbrow of de elite van het landsbestuur. Een dag eerder was hij 'dr Hirschfeld' (een frequent bezoeker van De Witte) tegengekomen. Toegegeven moest worden dat deze de gemeenschap van méér nut was dan het aardige, in bont gehulde 'kindje' dat dezelfde dag met haar 'welgevulde mama' tegenover Buitenhof in het etablissement Trocadéro had gezeten, 'doch niettemin - in het gelaat van de eeuwigheid, die alle carrières grauw maakt - zegt een glimlach van den heer Hirschfeld mij aanmerkelijk minder dan een van de andere zijde...'. Voor de lezers van Het Vaderland was de zevenendertigjarige directeur-generaal van Handel en Nijverheid Hans Max Hirschfeld kennelijk bekend genoeg om hem zonder nadere introductie als onderwerp van spot te laten fungeren. ${ }^{2}$ Echter, dat ruim zeventig jaar later nog altijd verhitte discussies over deze Nederlandse ambtenaar van Duits-Joodse afkomst gevoerd zouden worden, zullen Buitenhof/Elias en zijn lezers in 1936 niet hebben kunnen bevroeden.

Hirschfeld dankt zijn huidige relatieve bekendheid aan zijn werk tijdens de bezetting als secretaris-generaal. Toen de regering na de Duitse inval naar Londen uitweek, werd de verantwoordelijkheid voor de departementen van Handel, Nijverheid en Scheepvaart en Landbouw en Visserij aan hem overgedragen. Hij werd daarmee de eindverantwoordelijke voor de economische

1 Met dank aan Liesbeth van de Grift, Alexander van Kessel, Gert van Klinken, Herman Langeveld en Krijn Thijs voor hun commentaar op een eerdere versie van dit stuk naar aanleiding van Meindert Fennema en John Rhijnsburger, Dr. Hans Max Hirschfeld. Man van bet grote geld (Amsterdam 2007).

2 In het (via internet te raadplegen) digitale archief van Het Vaderland zijn dan ook honderden berichten uit de jaren dertig te vinden waarin melding gemaakt wordt van Hirschfelds vele binnenlandse werkbezoeken en lezingen, alsmede van zijn handelspolitieke besprekingen, vooral met nazi-Duitsland: http://kranten.kb.nl. Ook het archief van de Leeuwarder Courant (dat eveneens via internet kan worden ingezien) bevat een groot aantal artikelen over Hirschfelds werkzaamheden: http://www.archiefleeuwardercourant.nl. 